\title{
COMPARISON OF THE CORONAL MARGINAL MICROLEAKAGE OF TOOTH COLORED RESTORATIVE MATERIALS.
}

\footnotetext{
1. BDS, M.Phil

Assistant Professor

Department of Science of Dental Materials

Bacha Khan Dental College,

Mardan.

2. BDS, FCPS

Associate Professor

Department of Prosthodontics

Peshawar Dental College, Peshawar

3. BDS, M.Phil

Assistant Professor

Department of Pathology

Khyber Medical College, Peshawar.

4. BDS, M.Phil

Lecture

Bacha Khan Dental College,

Mardan.
}

Correspondence Address:

Dr. Muhammad Raza

Gucha Captan Lal Khan,

Bazar Topan Wala, Dera Ismail, Khan.

hmraza77@yahoo.com

Article received on:

27/10/2018

Accepted for publication:

15/07/2019

\section{Syed Muhammad Awais ${ }^{1}$, Muhammad Raza ${ }^{2}$, Syed Umer Farooq ${ }^{3}$, Sana Ahmad}

\begin{abstract}
Objectives: To compare the coronal marginal microleakage three types of available tooth colored restorative materials. Study Design: This in vitro comparative experimental study. Setting: Department of Science of Dental Materials, Sardar Begum Dental College. Period: July 2017 to November 2017. Material \& Methods: Marginal micro-leakage of three tooth colored dental restorative materials were evaluated. In this study 55 specimens were divided into five groups, three experimental and two control groups. For experimental groups (I, II, III), 15 specimens each were allocated while five specimens each were allocated to positive control and negative control group. Standard Class I cavities were restored using Self-cured Glass lonomer (Shofu Inc Japan), Resin Modified Glass lonomer Cement (Kavitan LC; Spofa Dental Kerr Company) and Posterior Composites (Filtek P60; 3M ESPE). After thermo cycling and immersion in $2 \%$ methylene blue dye solution, the teeth were sectioned and the dye penetration depth measurement was done for each specimen with a periodontal probe in $\mathrm{mm}$ with the aid of magnifying lens. Analysis of variance (ANOVA) was used to assess the significant difference in coronal marginal microleakage of different materials by using SPSS. Results: It was found that there was a statistically significant difference $(p<0.05)$ in the microleakage of Group II and Group III when compared with group I but no statistically significant difference in the micro-leakage values of Group II and Group III was observed. Conclusion: All the restorative materials were unable to prevent the microleakage completely. Filtek P60 displayed minimum mean microleakage followed by Kavitan LC while the mean microleakage of Self-cured shofu Glass lonomer was found to be maximum.
\end{abstract}

Key words: $\quad$ Composite, Glass lonomer, Microleakage, Restorative Material.

Article Citation: Awais SM, Raza M, Farooq SU, Ahmad S. Comparison of the coronal marginal microleakage of tooth colored restorative materials. Professional Med J 2020; 27(1):11-15. DOI: 10.29309/TPMJ/2020.27.1.362

\section{INTRODUCTION}

Clinical longevity of dental restoration is one of the objectives of dental treatment. One of the most important factors in reducing the life of tooth colored restorative materials is micro-leakage. ${ }^{1}$ This problem of micro-leakage in tooth colored restorative material is due to polymerization shrinkage ${ }^{2}$, which may cause failure of the bond between material and tooth structure which intern may result in micro-space between tooth surface and the material. ${ }^{3}$ Through these micro-spaces bacteria, toxic or non-toxic fluids, molecules or ions can pass which may cause hypersensitivity, secondary caries and ultimately failure of restoration. ${ }^{4,5}$ Coronal micro-leakage of different tooth colored materials has been observed in different studies, providing some important information regarding their sealing capability. ${ }^{2-8}$
Researchers have made tremendous efforts to minimize micro-leakage for obtaining good coronal seal and long lasting restorations. ${ }^{9}$

The ultimate success of a material is indicated by its longevity in the oral cavity. As the initial in vitro screening of new materials does not always reveal their full limitations or possibilities, clinical testing of new systems remains the ultimate proof of effectiveness. So this in-vitro study was designed to assess and compare marginal sealing ability of three different commonly used tooth colored restorative materials (Self cure Glass Ionomer cement, Resin Modified Glass Ionmer Cement and Posterior Packable Composites) due to increased patients and dentists demand, for longevity and reliability of the tooth color restorative materials in reducing the microleakage which will influence 
their clinical use. Similarly the clinicians will be in a better position to choose/prefer one material over the other. This will ultimately prove better for a patient in terms of comfort, clinical services, economical concerns and psychological benefits.

\section{MATERIALS \& METHODS}

This in vitro comparative experimental study was conducted at Department of Science of Dental Materials, Sardar Begum Dental College, Gandhara University. Fifty five healthy sound human premolar teeth extracted for orthodontic treatment purpose were used in this study. In order to disinfect and have clean surfaces, all the teeth were placed in $2 \%$ sodium hypochlorite solution for 48 hours. In this study, all 55 specimens were divided into five groups, three experimental and two control groups. For experimental groups (I, II, III), 15 specimens each were allocated while five specimens each were allocated to positive control and negative control group. Group I was assigned to Self-Cure Glass lonomer cement (Shofu, Inc Japan), Group II were assigned to Resin Modified Glass lonmer Cement (Kavitan, LC) and group III were assigned to Posterior Composites (Filtek P60; 3M ESPE). In the negative control group five prepared cavities were completely filled with inlay wax (Kerr, Oklahoma, USA). Five prepared teeth in the positive controls were not filled with any restorative materials; only a small dry cotton pellet was placed.

Class I cavity standardized to a size of $3 \times 2 \times 2 \mathrm{~mm}$ dimensions was prepared in each tooth by using round bur and straight fissured diamond burs (No.010) using high speed cold water air turbine. Burs were replaced after every eight preparations. After cavity preparation all the specimens were stored in normal saline till restorations were placed. The cavities of all specimens in three groups were restored with respective restorative material as suggested by manufacturer's manual. After restoring cavities, the samples were radio graphed to verify their uniformity and density. The restorations specimens in each group were finished and polished with polishing wheel (Bego Made in Germany). The specimens were then stored at $37^{\circ} \mathrm{C}$ in distilled water for 7 days. The coronal and radicular surfaces of the teeth except the restorations and $1 \mathrm{~mm}$ around the margins of restorations were isolated with two layers of nail varnish in order to prevent dye penetration (Diana of London France). The nail varnish was allowed to dry for 12 hours before thermo cycling. The root apices were covered with sticky wax (Kemdent swildone wiltshire uk).

All the specimens in each group were subjected to thermo cycling for ageing. According to ISO requirement 500 cycles were delivered to each specimen by using two controlled Digital Water Bath and an aluminum container of crushed ice in refrigerator (PEL), at the temperature of at $5^{\circ}$ to $55^{\circ} \mathrm{C}$ for 30 seconds. Crushed ice was changed after every 10 cycles.

After then each specimen was immersed in container containing $10 \mathrm{ml}$ of $2 \%$ solution of methylene blue (Beijing Solar bio Science and Technology Co) for 24 hours. After removing the teeth from dye, samples were carefully rinsed under the tap water for 15 minutes, Then samples were shifted to specimen bottles containing distilled water till the process of sectioning.

Longitudinal sections was prepared with a diamond disk (speedy ceramic disc prodont holliger, France), in bucco-lingual direction, dividing the restoration at its midpoint mesiodistaly exposing the tooth interface from cavosurface margin to the pulpal wall.

The sectioned teeth were observed for dye penetration depth measurements for each specimen with a periodontal probe in $\mathrm{mm}$ with the aid of magnifying lens and scored for the degree of dye penetration in the occlusal cavity walls. In this way three reading were taken and then mean was used for further statistical analysis. The data were analyzed by using Statistical Package for Social Science (SPSS version 21). Analysis of variance (ANOVA) was used with $p$ value $<0.05$ was considered as statistically significant to assess the significant difference in coronal marginal micro leakage of the research specimens.

Scoring Criteria For Measurement Dye Penetration 
Score 0: No dye penetration.

Score 1: Dye penetrates upto $1 \mathrm{~mm}$.

Score 2: Dye penetrates upto $2 \mathrm{~mm}$.

Score 3: Dye penetrates upto $3 \mathrm{~mm}$ or more.

\section{RESULTS}

In this study a total of 55 extracted premolar teeth with class I cavity were used for evaluation of microleakage. The teeth were randomly assigned to Self-Cure Glass Ionomer cement (Shofu Inc Japan), Resin Modified Glass Ionmer Cement (Kavitan LC) and Posterior composites (Filtek P60; 3M ESPE) as group I, II and III respectively and control group (positive and negative) of 10 teeth. Data were collected and analyzed using SPSS version 19 and $p$ value of $<0.05$ was considered as statistically significant.

All the specimens in each group were evaluated for microleakage by dye penetration using scale ranged from " 0 to 3 " for measurement. Value of "0" meant no evidence of dye penetration, while value of 1 shows dye penetration up to $1 \mathrm{~mm}, 2$ shows dye penetration up to $2 \mathrm{~mm}$, and 3 presenting dye penetration covering the axial wall (Table-l).

\begin{tabular}{|l|c|c|c|c|}
\hline Groups & Score 0 & Score 1 & Score2 & Score 3 \\
\hline Group I & 0 & 0 & 1 & 14 \\
\hline Group II & 2 & 13 & 0 & 0 \\
\hline Group III & 5 & 10 & 0 & 0 \\
\hline
\end{tabular}

Table-I. Value of microleakage number of specimens.

The specimens in negative control group showed no dye penetration and the specimens in positive control group demonstrated maximum dye penetration which was beyond the score 3 . In group I, the minimum score was 2 and maximum was 3 and mean microleakage value was 2.93 while the minimum, maximum and mean microleakage value for group II and III are given in the (Table-II)

It is evident that Group II, III had a more zero scores than that observed with Group I, showing better sealing ability of Group II, III than Group I. whereas Group I had the higher number of specimens with score of 3 as compare to Group II and III. It was found that there was no significant difference in the mean microleakage values of Group II and Group III, while a statistically significant difference $(p<0.05)$ was observed in the microleakage of Group II and Group III with group I. results of Post hoc analysis of variance (ANOVA) test there was significant difference in the microleakage values of Group I with Group II and III and is no difference between Group II and III.

\section{DISCUSSION}

Micro leakage has been defined as measure of the performance, longevity and success of restorative material by the dentist, clinician and researchers. ${ }^{1}$ The present study compared the degree of marginal microleakage of Shofu glass lonomer, Kavitan LC and P60 composites at the tooth restoration interface, evaluated by dye penetration technique. It was found that no material was able to completely block/prevent microleakage. Ideally there is no such material exist which is perfectly adaptive and adhesive to tooth structure that shows no microleakage. ${ }^{3}$

In this study standardized Class I cavities to a size of $3 \times 2 \times 2 \mathrm{~mm}$ were prepared with high speed air Turbine and water spray coolant. Class I cavities were selected because of its configuration or ' $\mathrm{C}$ ' factor, which corresponds to the ratio between the number of bounded and unbounded surfaces. ${ }^{10}$

\begin{tabular}{|c|c|c|c|c|c|c|c|c|}
\hline \multirow{2}{*}{ Group } & \multirow{2}{*}{$\begin{array}{l}\text { Number of } \\
\text { specimens }\end{array}$} & \multirow{2}{*}{ Mean } & \multirow{2}{*}{$\begin{array}{c}\text { Std. } \\
\text { Deviation }\end{array}$} & \multirow{2}{*}{$\begin{array}{l}\text { Std. } \\
\text { Error }\end{array}$} & \multicolumn{2}{|c|}{$95 \%$ confidence interval for mean } & \multirow{2}{*}{ Minimum } & \multirow{2}{*}{ Maximum } \\
\hline & & & & & Lower Bound & Upper Bound & & \\
\hline $\mathrm{I}$ & 15 & 2.933 & .2582 & .0667 & 2.790 & 3.076 & 2.0 & 3.0 \\
\hline III & 15 & .667 & .3519 & .0909 & .672 & 1.062 & .0 & 1.0 \\
\hline Total & 45 & 1.489 & 1.1000 & .1640 & 1.158 & 1.819 & .0 & 3.0 \\
\hline
\end{tabular}


Dye leakage method used in the study due to its simplicity, inexpensive, fast technique and not requiring complex laboratory equipment. Methylene blue dye was used for dye leakage assessment because it easily penetrates the water compartment of the tooth, does not react with the hard tissues and is readily detected under visible light. ${ }^{11}$

Thermo cycling was done because it is a widely used method in dental research for ageing. ${ }^{12}$ The mean microleakage values of specimens in Group I (Shofu glass ionomer cement) was statistically different from group II (Kavitan LC) and III (Filtek P60) however, there were no significant difference in the results of groups II and III. The specimens in group III (Filtek P60) showed the best results as compared to the specimens in group I (Shofu glass ionomer cement). Shofu glass ionomer cement showed dye penetration to the full deepness while Filtek P60 and Kavitan LC showed less dye penetration at the tooth-restoration interface. These results are in accordance with the earlier studies done by Damman et al and Uranga in which it was concluded that composite resin leaked comparatively less than glass lonomer cement, composite resin proved better in terms of marginal seal. ${ }^{13,14}$

In this study higher dye leakage was observed in Conventional Glass lonomer Cement filling, may be due to the fact that there was no primer used. Another possible reason for the observed decreased leakage in the case of Composite resin in comparison with Conventional Glass lonomer Cement was the higher filler loading in the posterior packable composite type. Which resulted in lower polymerization shrinkage and lower coefficient of thermal expansion, thus improved the long-term bonding to tooth structure. It has been already reported in previous studies that RMGIC provides acceptable sealing at the margins of restorations. ${ }^{15} \mathrm{~T}$ Singla et al has done similar types of studies, having same study design and concluded the same results that resin modified glass lonomer showed less leakage than the conventional glass ionomer. ${ }^{16}$ longitudinal sections with limitation of that only the "sectioned part" of the restored cavity could be examined. The dye penetration may vary from one to another zone of the same tooth. ${ }^{17}$ In this study only single surface was used for the extent of dye penetration which was the "sectioned surface" This could make it possible for the observers to oversight the extent of dye penetration in all directions.

The results of this study concludes that the sealing capability of conventional glass lonomer cement is less as compared to posterior composite and resin modified glass lonomer cements in terms of microleakage while sealing capability of posterior composite is more as compared to resin modified glass lonomer cements. It is recommended that clinical trials should be done.

Copyright $(15$ July, 2019.

\section{REFERENCES}

1. A Diwanji. Comparative evaluation of microleakage of three restorative glass ionomer cements: An in vitro study. J Nat Sci Biol Med. 2014 Jul-Dec; 5(2): 373-377.

2. Bayram HM, Berkan Çelikten, Emre Bayram, Alperen Bozkurt. Fluid flow evaluation of coronal microleakage intraorifice barrier materials in endodontically treated teeth. Eur J Dent. 2013 Jul-Sep; 7(3): 359-362.

3. Khoroushi M1, Karvandi TM, Kamali B, Mazaheri H. Marginal microleakage of resin-modified glassionomer and composite resin restorations: Effect of using etch-and-rinse and self-etch adhesives. Indian J Dent Res. 2012 May-Jun; 23(3):378-83. doi: 10.4103/0970-9290.102234.

4. Pinna R, Usai P, Filigheddu E, Garcia-Godoy F, Milia $E$. The role of adhesive materials and oral biofilm in the failure of adhesive resin restorations. $\mathrm{Am} \mathrm{J}$ Dent. 2017 Oct; 30(5):285-292.

5. Gurgan S, Kutuk ZB, Ergin E, Oztas SS, Cakir FY. Fouryear randomized clinical trial to evaluate the clinical performance of a glass ionomer restorative system. Oper Dent 2015; 40:134-43.

6. Leprince JG, Palin WM, Vanacker J, Sabbagh J, Devaux J, Leloup G. Physico-mechanical characteristics of commercially available bulk-fill composites. J Dent 2014; 42:993-1000.

The extent of dye penetration was measured in 
7. Eronat N, Yilmaz E, Kara N, Topaloglu AA. Comparative evaluation of microleakage of nano-filled resinmodified glass ionomer: An in vitro study. Eur J Dent 2014; 8:450-5.

8. Kalmowicz J, Phebus JG, Owens BM, Johnson WW, King GT. Microleakage of Class I and II composite resin restorations using a sonic-resin placement system. Oper Dent 2015; 40:653-61.

9. Baig MM, Zaid MM, Al-Muhaiza AJM. Microleakage evaluation in restorations using different resin composite insertion techniques and liners in preparations with high c-factor - An in vitro study. King Saud Uni J of Dent Sci 2013; 4:57-64.

10. Motaz A. Ghulman, "Effect of cavity configuration (C Factor) on the marginal adaptation of low-shrinking composite: A comparative ex vivo study," International Journal of Dentistry, vol. 2011, Article ID 159749, 8 pages, 2011. https://doi.org/10.1155/2011/159749.

11. Alani $A H$, Toh $C G$. Detection of microleakage around dental restorations: A review. Oper Dent 1997; 22:173-85

12. Kiomarsi N, Saburian P, Chiniforush N, Karazifard M-J, Hashemikamangar S-S. Effect of thermo cycling and surface treatment on repair bond strength of composite. Journal of Clinical and Experimental Dentistry. 2017; 9(8):e945-e951. doi:10.4317/ jced.53721.
13. D Damman, Renata Grazziotin-Soares. Coronal microleakage of restorations with or without cervical barrier in root-filled teeth. Rev. Odontociênc. 2012; 27:3 Porto Alegre

14. Uranga A, Blum JY, Esber S, Parahy E, Prado C. A comparative study of four coronal obturation materials in endodontic treatment. J Endod 1999; 25:178-80.

15. Jaya G, Sunil K. Comparative evaluation of microleakage in Class $\mathbf{V}$ cavities using various glass ionomer cements: An in vitro study. Journal of Interdisciplinary Dentistry 2012

16. Singla T,Pandit IK, Gugnani N,Gupta M. An evaluation of microleakage of various glass ionomer based restorative materials in deciduous and permanent teeth: An in vitro study. Saudi Dent J, 2012; 24(1):35-42.

17. Sooraparaju SG, Kanumuru PK, Nujella SK, Konda KR, Reddy KBK, Penigalapati S. A comparative evaluation of microleakage in Class $\mathbf{V}$ composite restorations. International Journal of Dentistry. 2014; 60.

\begin{tabular}{|c|c|c|c|}
\hline \multicolumn{4}{|c|}{ AUTHORSHIP AND CONTRIBUTION DECLARATION } \\
\hline Sr. \# & Author(s) Full Name & Contribution to the paper & Author(s) Signature \\
\hline 1 & Syed Muhammad Awais & Principal investigator. & \\
\hline 2 & $\begin{array}{l}\text { Muhammad Raza } \\
\text { Syed Umer Farooq }\end{array}$ & $\begin{array}{l}\text { Objective setting, research } \\
\text { designing and drafting. } \\
\text { Literature review. }\end{array}$ & \\
\hline 4 & Sana Ahmad & Drafting and paper writ-up. & \\
\hline
\end{tabular}

